\title{
Neurobiology of Kleptomania: an overview
}

\author{
Ajish G Mangot
}

\section{Abstract}

Kleptomania is a psychiatric manifestation frequently encountered in neurological conditions, especially Parkinson's disease. This disorder has traditionally been considered to be a part of the obsessive compulsive spectrum disorder, but recently the focus has shifted to possible associations with addiction disorders. There are no FDA approved medications for the treatment of kleptomania. While serotonergic medications form the mainstay treatment, questions have been raised regarding their effectiveness, especially with reports emerging about these medications paradoxically inducing kleptomania. Keeping these points in perspective, a short review of literature was performed about the neurobiology of kleptomania, and a treatment algorithm is suggested based on the findings.

Key words: kleptomania, serotonin, dopamine, opioid, glutamate

SL J Psychiatry 2014; 5(2) 2-4

\section{Introduction}

Kleptomania is characterised by the repetitive, uncontrollable urge to steal things for reasons other than personal use or financial gain. After much debate, at present kleptomania has been included as a separate diagnostic entity in DSM 5 under 'Disruptive, Impulsecontrol, and Conduct Disorders'(1). Although this phenomenon has been described in the literature for over two centuries, its neurobiological correlates are still a matter of debate and research.

\section{Methodology}

A literature search was conducted in the electronic database PubMed, using the search terms of kleptomania, serotonin and dopamine. Articles focusing on the neurobiology of kleptomania, written in English, were included. Relevant references quoted within the selected articles were also retrieved and examined.

\section{Controversial role of serotonin in kleptomania}

The neurobiological correlates of kleptomania have been steadily gaining credence over the last few years. Decades of research show that dopamine and serotonin are the primary neurotransmitters involved in the pathogenesis and management of kleptomania, respectively $(2,3)$. Selective serotonin reuptake inhibitors (SSRIs) have been used as first line agents for treating kleptomania (3). Kleptomania has often been considered to be a part of obsessive compulsive spectrum disorders (OCSD) which include diverse conditions like other impulse control disorders (ICD), and disorders characterised by preoccupation with body appearance or sensation. These disorders have traditionally responded well to SSRIs at the maximum recommended dosages (4).

Paradoxically, there are case roports of kleptomania being induced in adults who were started on SSRIs for depression (5). A recent Indian paper also reported a similar manifestation while on fluvoxamine treatment for obsessive compulsive disorder (6). Other diverse unlawful behaviours such as auto theft, robbery, shoplifting and property offenses have also been reported after starting SSRI treatment for depression (7). Theses manifestations may be partly explained by the phenomenon of effective depletion of synaptic serotonin, following acute administration of SSRIs, through the serotonin mediated action on its auto-receptor (8). Another explanatory hypothesis is the theory that long term use of SSRIs may lead to down-regulation of serotonin receptor production (9).

\section{Kleptomania and dopamine}

While the role of serotonin is getting less clear, the role of dopamine is gaining importance in the pathophysiology of kleptomania, especially in neurological disorders such as Parkinson's disease (PD). Kleptomania is seen as an emergent side effect of the use of dopamine agonists in PD (10). Other ICDs like pathological gambling, compulsive shopping, compulsive eating and hypersexuality have also been reported with the use of dopamine agonists (10). This phenomenon is explained by the overdose theory (11). In PD, ventral striatal dopamine is preserved relative to dorsal striatal activity; thus, dopaminergic treatment titrated to alleviate motor dorsal striatal deficiencies may result in an 'over-dosing' in ventral cortico-striatal cognitive and limbic pathways. In support of this hypothesis, there is preliminary evidence for the benefit of atypical antipsychotics for treatment of ICDs, including kleptomania (12). 
At the same time, serotonergic and dopaminergic systems are not mutually exclusive. One hypothesis is that an alteration in dopamine levels post SSRI initiation leads to the acute rise in impulsivity seen in behavioural activation or disinhibition. SSRIs are known to sensitize dopamine (D2) receptors (13). It is considered as one of the mechanisms of its antidepressant action. Many serotonin receptors (5-HT $1 \mathrm{~A} / 1 \mathrm{~B} / 2 \mathrm{~A} / 3 / 4)$ facilitate dopamine release while 5 -HT2C mediates an inhibitory effect (14). Thus it is suggested that the apparent effectiveness of SSRIs in kleptomania may be due to dopaminergic modulation, rather than primary effect on the serotonergic system.

\section{Kleptomania as behavioural addiction}

ICDs in the general population have epidemiological and phenomenological overlaps with substance addiction, and they are classified by some as behavioural addictions. Kleptomania shares certain features with substance use disorders (SUDs) (15). This possible association between the two phenomena has led to the trial use of naltrexone in the treatment of kleptomania with favourable results (16). Based on these positive results, a pilot study was recently conducted using memantine for kleptomania, and it was reported to be effective in reducing the impulsivity and urge to shoplift, together with improvement of mood and psychosocial functioning (17).

Therefore along with the erstwhile serotonin and dopamine, treatment of kleptomania is further complicated with the involvement of opioid and glutamate systems. In fact a variety of genes modulating all the above systems have been implicated in the pathogenesis of kleptomania (2).

\section{Kleptomania and comorbidities}

Kleptomania is often associated with other psychiatric disorders including depression, addiction and personality disorders. The incidence of kleptomania in a cohort of inpatients with other psychiatric disorders has been reported as $7.8 \%$ (18). Structural brain lesions, including head trauma, have also been associated with kleptomania (19). While patients with kleptomania generally do not show deficits on neuropsychological testing, impaired executive functions may be seen in severe kleptomania. This may suggest a link between frontal lobe syndrome and kleptomania, at least in severe forms (20).

\section{Summary}

A key finding is that there are varying reported neurobiological correlates of kleptomania, as well as a range of explanatory theories -from OCSD to behavioural addiction. Since kleptomania is often found comorbid with other psychiatric or neurological disorders, a treatment algorithm for kleptomania based on the detailed history of psychiatric or neurological comorbidities and medication history should be considered.
SSRIs should still be considered as first line agents, as they are time tested for ICD and OCSD, especially if associated with depression and pre-morbid impulsive traits. Dopaminergic modulation seems equally important, and addition of atypical antipsychotic to augment SSRIs is worth considering. Medications with fewer extrapyramidal side effects may be considered in patients with kleptomania and PD, along with adjustment of dosage or shift to another dopamine agonist. Mood stabilisers could be considered if there is a past history of mania or hypomania; kleptomania developing in response to treatment of a depressive disorder could be conceptualised as a selective switch to hypomania similar to the concept of SSRI induced disinhibition of libido (21). As the final option, naltrexone and memantine may also be considered for treatment, especially in patients with comorbid or family history of substance use disorders.

\section{Conclusion}

While medications which affect the serotonin system have been the most widely studied in the treatment of kleptomania, their clinical effects have been modest, inconsistent or even paradoxical. Medications that affect dopaminergic neurotransmission have received less research attention. Developments in neurobiology, coupled with newer pharmacological models involving the opioid and glutamate systems will surely further our understanding of the pathophysiology and pharmacotherapy of kleptomania. Kleptomania is the final common manifestation of various underlying pathogenic mechanisms, and there is a need for a rational approach to treatment, rather than the blanket use of one agent. Further randomised trials taking into account all these factors will help in elucidating a definitive management plan.

\section{Declaration of interest \\ None declared}

Ajish G Mangot, People's College of Medical Sciences \& Research, Bhanpur, Bhopal, Madhya Pradesh, India.

Email: dr.ajish@outlook.com

\section{References}

1. American Psychiatric Association. Diagnostic and statistical manual of mental disorders (5th ed.). Washington, DC; American Psychiatric Association: 2013.

2. Cilia R, van Eimeren T. Impulse control disorders in Parkinson's disease: seeking a roadmap toward a better understanding. Brain Struct Funct 2011; 216: 289-99.

3. Lepkifker E, Dannon PN, Ziv R, Ziv R, Iancu I, Horesh $\mathrm{N}$, Kotler $\mathrm{M}$. The treatment of kleptomania with serotonin reuptake inhibitors. Clin Neuropharmacol 1999; 22: 40-3.

4. Hollander E. Treatment of obsessive-compulsive spectrum disorders with SSRIs. Br J Psychiatry 1998; 173(Suppl 35): 7-12. 
5. Kindler S, Dannon PN, Lancu I, Sasson Y, Zohar J. Emergence of kleptomania during treatment for depression with serotonin selective reuptake inhibitors. ClinNeuropharmacol 1997; 20: 126-9.

6. Gupta P. Emergence of kleptomania during treatment for obsessive compulsive disorder with fluvoxamine. Indian J Psychiatry 2014; 56: 100-1.

7. Glancy GD. Antisocial ideation and activities precipitated by the administration of SSRIs. Can J Psychiatry 1993; 38: 695.

8. Celada P, Puig M, Amargos-Bosch M, Adell A, Artigas F. The therapeutic role of 5-HT1A and 5-HT2A receptors in depression. J of Psychiatry and Neurosci 2004; 29(4): 252-65.

9. Constantino JN, Liberman M, Kincaid M. Effects of serotonin reuptake inhibitors on aggressive behavior in psychiatrically hospitalized adolescents: results of an open trial. J Child Adolesc Psychopharmacol 1997; 7: 31-44.

10. Voon V, Mehta AR, Hallett M. Impulse control disorders in Parkinson's disease: recent advances. Curr Opin Neurol 2011; 24: 324-30.

11. Cools R. Dopaminergic modulation of cognitive functionimplications for L-DOPA treatment in Parkinson's disease. Neurosci \& Biobehav Rev 2006; 30: 1-23.

12. Ravindran A, da Silva T, Ravindran L, Richter MA, Rector NA. Obsessive-Compulsive Spectrum Disorders: A Review of the Evidence-Based Treatments Can J Psychiatry 2009; 54: 331-43.
13. Willner P, Hale AS, Argyropoulos S. Dopaminergic mechanism of antidepressant action in depressed patients. J Affect Disord 2005; 86: 37-45.

14. Alex KD, Pehek EA. Pharmacologic mechanisms of serotonergic regulation of dopamine neurotransmission. Pharmacol Ther 2007; 113: 296-320.

15. Marks I. Behavioural (non-chemical) addictions. Br J Addict 1990; 85: 1389-94.

16. Grant JE, Kim SW, Odlaug BL. A double-blind, placebocontrolled study of the opiate antagonist, naltrexone, in the treatment of kleptomania. Biol Psychiatry 2009; 65: 600-6.

17. Grant JE, Odlaug BL, Schreiber LR, Chamberlain SR, Won Kim S.. Memantine reduces stealing behavior and impulsivity in kleptomania: a pilot study. Int Clin Psychopharmacol 2013; 28: 106-11.

18. Grant JE, Levine L, Kim D, Potenza MN. Impulse control disorders in adult psychiatric inpatients. Am J Psychiatry 2005; 162: 2184-8.

19. Aizer A, Lowengrub K, Dannon PN. Kleptomania after head trauma: two case reports and combination treatment strategies. Clin Neuropharmacol 2004; 27: 211-5.

20. Grant JE, Odlaug BL, Wozniak JR. Neuropsychological functioning in kleptomania. Behav Res Ther 2007; 45: 1663-70.

21. Greil W, Horvath A, Sassim N, Erazo N, Grohmann R. Disinhibition of libido: an adverse effect of SSRI? J Affect Disord 2001; 62: 225-8. 